- RAM, REV. ADM. MACKENZIE, V. 12, N. 5 • SÃO PAULO, SP • SET./OUT. 2011 •ISSN 1518-6776 (impresso) • ISSN 1678-6971 (on-line) • Submissão: 5 abr. 2010. Aceitação: 22 jul. 2011. Sistema de avaliação: às cegas dupla (double blind review). UNIVERSIDADE PRESBITERIANA MACKENZIE. Walter Bataglia (Ed.), p. 43-67.

\title{
1 APROPRIAÇÃO DOS SABERES \\ ADMINISTRATIVOS: UM OLHAR ALTERNATIVO SOBRE O DESENVOLVIMENTO DA ÁREA
}

\section{AMON NARCISO DE BARROS}

Doutorando do Centro de Pós-Graduação e Pesquisas em Administração da Universidade Federal de Minas Gerais (UFMG). Mestre em Administração pelo Centro de Pós-Graduação e Pesquisas em Administração da UFMG. Avenida Antônio Carlos, 6.627, Sala 4012, Pampulha, Belo Horizonte - MG - Brasil - CEP 32170-901

E-mail: amonbarros@gmail.com

\section{RAFAELA COSTA CRUZ}

Mestra em Administração pelo Centro de Pós-Graduação e Pesquisas em Administração da Universidade Federal de Minas Gerais (UFMG).

Professora do Departamento de Administração da Universidade Federal de Uberlândia (UFU). Avenida João Naves de Ávila, 2.121, Bloco IF, Sala IF 238, Santa Mônica, Uberlândia - MG - Brasil - CEP 38408-100 E-mail: correiodarafaela@yahoo.com.br

WESCLEY SILVA XAVIER

Doutorando do Centro de Pós-Graduação e Pesquisas em Administração da Universidade Federal de Minas Gerais (UFMG). Mestre em Administração pelo Centro de Pós-Graduação e Pesquisas em Administração da UFMG. Avenida Antônio Carlos, 6.627, Sala 4012, Pampulha, Belo Horizonte - MG - Brasil - CEP 32170-901

E-mail: wescleysxavier@yahoo.com.br

\section{ALEXANDRE DE PÁDUA CARRIER}

Doutor em Administração pela Faculdade de Ciências Econômicas da Universidade Federal de Minas Gerais (UFMG). Professor do Departamento de Ciências Administrativas da UFMG. Avenida Antônio Carlos, 6.627, Sala 4012, Pampulha, Belo Horizonte - MG - Brasil - CEP 32170-901

E-mail: alexandre@face.ufmg.br

\section{GUSTTAVO CESAR OLIVEIRA LIMA}

Mestre em Administração pelo Centro de Pós-Graduação e Pesquisas em Administração da Universidade Federal de Minas Gerais (UFMG).

Professor da Faculdade de Ciências Administrativas e Contábeis de Itabira da Fundação Comunitária de Ensino Superior de Itabira (Funcesi).

Rua Venâncio Augusto Gomes, 50, Prédio 3, Sala 202, Major Laje de Cima, Itabira - MG - Brasil - CEP $35900-842$ E-mail: gusttavocesarlima@bol.com.br 


\section{RESUMO}

O presente trabalho tem como objetivo colocar em relevo uma visão alternativa no que se refere ao estabelecimento dos saberes gerenciais. Busca-se ressaltar a importância dos praticantes para que os saberes administrativos circulassem e, mesmo, chegassem a existir, em um contexto no qual não havia estabelecimentos de ensino superior em Administração. Assim, a transmissão desses conhecimentos e a legitimação desses saberes ainda não haviam se integrado às normas de produção de ciência, mas já se estabeleciam por outras vias que não aquelas legitimadas institucionalmente. Em um primeiro momento, considera-se a importância dos estudos que coloquem a Administração sob perspectiva histórica, a fim de discutir seu presente com mais apuro. Esse é um movimento que vem ganhando força, em especial internacionalmente, e que, de modo recente, passou a influenciar alguns autores brasileiros (COSTA; BARROS; MARTINS, 20IO). Em sequência, apresenta-se a perspectiva foucaultiana que subsidiou a reflexão desenvolvida, especialmente a partir das proposições de Foucault (2008, 2009) sobre a formação dos discursos e do estabelecimento dos saberes. Acredita-se que a reflexão acerca do estabelecimento de um regime de produção de verdade similar ao da ciência é elemento crucial para compreender o esquecimento do saber do praticante quando se discorre sobre o desenvolvimento do saber administrativo. Buscou-se, também, trazer elementos que permitissem discutir a formação do campo do saber administrativo e, especialmente, seu desenvolvimento no Brasil. O trabalho chega à conclusão de que, embora sejam, em geral, marginalizados, os saberes práticos foram importantes na formação do campo

44 do saber administrativo, especialmente no período que precede seu estabelecimento no interior do regime de produção de verdades científicas.

\section{PALAVRAS-CHAVE}

Administração; Ensino; Conhecimento; Foucault; História. 


\section{INTRODUÇÃO}

O papel dos praticantes ${ }^{1}$ de ações administrativas para a consolidação do que hoje é conhecido como gestão, especialmente o exercido antes do estabelecimento do ensino superior em Administração no Brasil, é, muitas vezes, ignorado. Assim, o objetivo deste trabalho é destacar um olhar alternativo possível para o desenvolvimento dos saberes administrativos e das teorias gerenciais. $\mathrm{O}$ reconhecimento da gestão como atividade relevante se legitima somente na sua formalização como algo que possa ser sistematizado, transmitido e apreendido, nos moldes educacionais tradicionais. Tanto no Brasil como em Portugal, as primeiras experiências relacionadas ao ensino de assuntos correlatos à administração se deram nas aulas de comércio (PELEIAS et al., 2007; RODRIGUES; GOMES; CRAIG, 2002), tendo sido continuadas no Brasil no ensino comercial (SANSON; NICOLAU, 2006), o qual tinha um caráter eminentemente prático. O comércio permitiu, ainda, a ocupação e o desenvolvimento econômico no país, sendo uma importante atividade econômica² .

No Brasil, desde a colonização, pelo menos, a atividade comercial lidou com a compra e venda de produtos, muitas vezes ligada à administração de casas comerciais que serviam de depósito e de local de negociação dos produtos ofertados que vinham de regiões distantes, especialmente da metrópole portuguesa (HONDA, 2005). A necessidade de algum tipo de controle era tanto externa quanto interna, e os saberes necessários para o desenvolvimento das atividades provinham, muitas vezes, do uso desses controles. Por um lado, havia a necessidade de pagar impostos sobre as mercadorias vendidas, o que tornava imperativa a adoção de controle da circulação das mercadorias e do dinheiro. Por outro, era necessário controlar estoques e preços, pela dificuldade de reabastecimento dos itens comerciados, já que muitos deles vinham da metrópole ou das grandes cidades brasileiras existentes à época.

Rodrigues, Gomes e Craig (2002) e Saas (I98I) atestam que, em grande medida, o ensino comercial teve início porque a transmissão de saberes relacionados aos controles escriturários mediante a relação mestre-aprendiz deixou de ser eficiente, em razão da crescente necessidade de mão de obra qualificada.

O uso do termo praticante remete aos sujeitos que empregam a prática cotidiana, da qual nos apropriamos com base na perspectiva desenvolvida por Certeau (2008). Essas práticas cotidianas estariam sujeitas a um conjunto muito grande de elementos que constitui diversos procedimentos. Embora deva ser assumido como um saber, não está estruturado em discurso, nem ao menos conta com a fixidez repetitiva dos ritos. Para Certeau (2008, p. 98), a apreensão da prática requer a observação da trajetória. A prática evoca "um movimento temporal no espaço, isto é, a unidade de uma sucessão diacrônica de pontos percorridos, e não a figura que esses pontos formam num lugar supostamente sincrônico ou acrônico".

2 A importância das atividades econômicas na ocupação dos territórios de Minas Gerais pode ser conferida, por exemplo, no texto de Paiva e Godoy (2002). 
Assim, segundo os autores, entre os séculos XVIII e XIX, a maneira tradicional de repassar os saberes, na qual um mestre ensinava a um aprendiz durante $o$ desenvolvimento das atividades, parecia ter se esgotado. O aumento do tamanho dos negócios, dos volumes transacionados e da complexidade envolvida nas negociações representava uma dificuldade à transmissão dos saberes aos aprendizes, o que contribuiu para a criação, em diversos países, de escolas que tinham como finalidade o ensino do comércio.

Esse curso histórico dos saberes administrativos que se origina - ou pelo menos tem seu ponto de inflexão - nas suas relações com atividades relacionadas ao comércio, todavia, atualmente parece ser relegado. Nas discussões estabelecidas na contemporaneidade, poucas são aquelas que manifestam interesses para as atividades desempenhadas pelos praticantes ao longo do tempo. A nosso ver, configura-se aqui uma lacuna, uma vez que esses praticantes podem ter contribuído em alguma medida na construção dos saberes administrativos, por exemplo, na figura dos que praticavam o comércio no passado.

Os saberes do pequeno comerciante ou do comerciante individual estão entre as várias questões "esquecidas" pelo saber técnico-científico empregado e/ou gerado na administração, sendo, em geral, considerados de pouca importância e comumente desprezados. Tais atitudes, em relação aos saberes não científicos, passam pela construção da ideia de que alguns saberes, por não se enquadrarem nos parâmetros necessários para serem considerados verdadeiros, são carentes de racionalidade e razoabilidade.

As práticas desses comerciantes, da perspectiva da racionalidade econômica utilitarista e calcada na ciência, estariam superadas e poderiam ser consideradas ineficientes no que se refere à alocação "ótima" de recursos. Entretanto, a desvalorização desses saberes "empíricos" está associada não, necessariamente, a uma atitude deliberada de gestores, acadêmicos e consultores. Ela se relaciona a um movimento próprio ao capitalismo, que não confere valor a esses saberes que são transmitidos por meio das relações estabelecidas a partir de lógicas que lhe são estranhas e que circulam em virtude de laços familiares ou afetivos, sendo adquiridos, construídos e significados na cotidianidade. Relaciona-se ainda às disputas pelo poder de dizer a verdade, elemento importante da constituição de nossa sociedade.

Nesse sentido, parece válido questionar se a maior parte das teorias gerenciais não se apropria de saberes que já estavam disseminados pelo corpo social, na forma de "saber prático" , ao mesmo tempo que, em face dessas teorias, a legitimidade é atributo apenas dos saberes transmitidos e chancelados institucional-

"Saber prático" é aqui designado como as técnicas e estratégias desenvolvidas pelos praticantes de comércio volante, que são tácitas. 
mente. O presente estudo fomenta a discussão sobre a apropriação dos saberes práticos pelas teorias gerenciais. Observa-se ainda a possibilidade da caracterização desses saberes como irracionais e, por isso, pouco elaborados. Salienta-se que a apropriação e hierarquização de outros saberes, como o do camponês, são discutidas por Aguiar (1992), Ribeiro (I995, 2003) e Ribeiro, Carrer e Nunes (2004), em uma óptica próxima da que abordamos aqui. Além disso, são lançadas aqui algumas ilações que refletem alguns achados nossos em uma pesquisa realizada, que se valeu de entrevistas semiestrutuadas com 33 comerciantes mineiros que atuavam em meados do século XX, sendo então utilizada como pano de fundo de parte das discussões estabelecidas ${ }^{4}$

Com vistas a atender à proposta estabelecida, este texto foi divido em seis partes, sendo a primeira esta introdução. Na segunda, busca-se apontar a perspectiva histórica a partir da qual este trabalho foi escrito. Em seguida, com base em uma perspectiva foucaultiana, discutem-se elementos da relação entre o saber legitimado e as práticas cotidianas, para trazer à tona algumas relações que permitam compreender melhor a abordagem do desenvolvimento dos saberes administrativos adotada neste ensaio. A quarta parte traz elementos que permitem compreender a consolidação do saber administrativo e gerencial tal como é conhecido, a partir dos elementos apresentados na seção anterior. Segue, então, uma discussão sumária que visa trazer a discussão anterior para uma esfera mais local, com especial enfoque para algumas especificidades do cenário nacional. Por fim, retomam-se os objetivos, as contribuições do artigo e suas deficiências, e apontam-se caminhos para pesquisas sobre o assunto.

\section{RELEVÂNCIA DO ESTUdO: O PASSADO REFLETIDO NO PRESENTE}

O estudo desenvolvido vai ao encontro da nova história, na qual se concebe não a existência de uma história, mas sim a existência de várias histórias (CARDOSO, I997), em que há a substituição de uma macro-história pela história da vida

4 Salienta-se, contudo, que a pesquisa realizada não visou estabelecer generalizações e que quaisquer observações que remetam a ela só podem ser utilizadas como ferramenta heurística na construção de novos trabalhos. Ao mesmo tempo, ressalta-se que não foram utilizados extratos das entrevistas realizadas na confecção deste trabalho, que se concentra no objetivo de avançar teoricamente na construção de relações possíveis entre os saberes e práticas dos pequenos comerciantes e os saberes que circulam no campo da Administração na contemporaneidade. Alerta-se, ainda, para o fato de que as ilações acerca das relações entre o comerciante e o estudo de seu filho foram observadas indiretamente pelos pesquisadores, nas conversas com os filhos e na observação dos comportamentos destes nas vezes em que estiveram presentes durante as entrevistas com os pais. Esse aspecto não fazia parte do roteiro dos entrevistadores previamente, tendo aparecido como uma "curiosidade" que pode vir a ser aprofundada posteriormente. 
cotidiana. De acordo com Burke (I992), a nova história diz respeito a toda atividade humana, baseada numa realidade social e culturalmente constituída, em que há preocupação com a opinião e os relatos de pessoas comuns e suas experiências de mudança social ou, como o próprio autor denomina, a história vista de baixo.

Assim, as discussões apresentadas não pretendem representar $a$ história dos saberes administrativos, mas apresentar uma dentre as diversas histórias possíveis. Partiu-se da reflexão acerca das práticas de comerciantes que atuavam antes da institucionalização das escolas superiores de Administração no país, para narrar uma aproximação possível do desenvolvimento dessa área, ou seja: uma versão dentre outras possíveis, como salienta Candiotto (2010). Cabe também ressaltar que as reflexões se deram a partir do cenário brasileiro, sem, contudo, excluir a possibilidade de haver aproximações com outros contextos.

Observa-se, também, que a área de Administração conta com estudos que se apropriam de elementos históricos há muito tempo, como as pesquisas desenvolvidas na área de business history (COSTA; BARROS; MARTINS, 20IO). Nessas pesquisas, as lentes estão voltadas à reconstrução da história de grandes empresas ou de personagens "importantes", ignorando outras pessoas que possam ter contribuído para a construção dos "grandes feitos", dos quais nos distanciamos neste trabalho. Boa parte dessa característica se deve à influência das obras de Chandler Jr. (I962) e Chandler Jr. e Tedlow (1985) que, segundo Booth e Rowlinson (2006), tornaram-se paradigma para essa disciplina.

Outros trabalhos que aproximam Administração e a história a partir de vieses mais compreensivos ou mais críticos - que inspiram este trabalho - vêm, entretanto, ganhando espaço, especialmente no exterior, em parte pelo interesse que os trabalhos de Michel Foucault continuam a despertar (ÜSDIKEM; KIESER, 2004; CARTER; MCKINLAY; ROWLISON, 2002). Leblebici e Shah (2004) enfatizam que, nos trabalhos de inspiração foucaultiana, a história é vista como uma narrativa construída por aquele que a conta e que se insere nas disputas de poder como um conhecimento que não é neutro.

Um olhar anacrônico com foco nas práticas de sujeitos que exerceram suas atividades no passado permitira evidenciar alguns "esquecimentos" que permeiam a história da construção das próprias teorias gerenciais. Como aponta Aguiar (1992), deve-se considerar que, por mais que os conhecimentos elaborados pelos sujeitos com base em suas práticas cotidianas pareçam estar calcados em tradições arcaicas, são submetidos a constantes transformações. Os homens, por viverem em coletividade, transformam o ambiente em que vivem ao mesmo tempo que também se transformam. Ao longo do tempo, os diferentes sujeitos não permanecem com o mesmo leque de saberes práticos que outrora. Adaptam-se aos novos cenários que vão sendo traçados ao longo do tempo, ainda que muitas vezes não consigam acompanhar a intensidade das transformações que acontecem ao seu redor. 
Tentar compreender as práticas das pessoas que viveram em tempos passados equivale a reconhecê-las como fenômenos de cultura e construção social, e não como mera irrupção instintiva. O desenvolvimento das sociedades e de suas culturas não se dá a partir da evolução de características que sempre estiveram presentes, "em germe", como se esta fosse um organismo que sofresse a seleção natural de suas características, que deixam de fazer efeito na medida em que deixam de existir. É a partir de uma visão evolucionista da história que se podem considerar as práticas e estratégias dos sujeitos que atuavam na área como casos isolados e que não exercem efeitos no presente, uma vez que este assumiria suas características em razão da evolução "natural" (LAWRENCE, I984). Assim, considerar o passado como caso isolado destinado ao desaparecimento depois da institucionalização dos cursos de Administração é reproduzir uma visão hegemônica da área que não atenta para as práticas do campo. Nesse sentido, faz-se aqui um esforço para dar razoabilidade às práticas pregressas, buscando conferir a elas um valor heurístico para a discussão teórica da gestão na contemporaneidade.

Pretende-se valorizar a história do campo da Administração não apenas nos moldes do mainstream da área, que se concentra sobre o desenvolvimento de grandes feitos ou de pessoas importantes, em um tom, geralmente, laudatório. Assim, concorda-se com Jacques (2006, p. 35, tradução nossa) - ainda que o autor centre esforços no campo teórico.

O argumento principal do mainstream dos estudos organizacionais, forma de produção de conhecimento superior à "mera" narrativa tal como a análise histórica ou interpretativa, é que a Administração é uma ciência aplicada, e, como ciência, seu desenvolvimento é baseado na evidência e na falseabilidade das correlações e causalidades mensuráveis.

Acredita-se que o campo das ciências ou dos saberes administrativos se estabeleceu mantendo relações com os saberes dos praticantes que, posteriormente, foram esquecidos e marginalizados. Tal ideia é reforçada pela relação que se estabelece entre as manifestações culturais e as práticas dos sujeitos, uma vez que as sociedades não refletem sobre problemas que não lhes sejam, em alguma medida, colocados empiricamente, e que tanto a esfera subjetiva quanto a objetiva se influenciam mutuamente. Tal ponto de vista está presente, por exemplo, em Bourdieu (1996, p. 57) que afirma que "não é possível tratar a ordem cultural, a episteme, como um sistema totalmente autônomo: quanto mais não seja, porque assim ficamos impedidos de dar conta das mudanças que ocorrem nesse universo separado". 
Assim, entende-se que é plausível refletir sobre como os praticantes podem ter influenciado a formação do campo dos saberes administrativos. Pensar-se-á essa relação a partir de um referencial foucaultiano, que também aponta a importância das práticas na constituição dos discursos, das epistemes e, mais importante, dos aspectos que atestam uma elaboração como sendo ou não verdadeira, a partir da constituição de formas institucionalizadas de atestar algo como pertencendo ao campo do verdadeiro ou do falso.

\section{RUPTURAS E CONTINUIDADES: CAMINHOS DO SABER}

Foucault (2008) aponta que o trabalho a que se propõe não intenta vasculhar o tempo em busca de abarcar todo o conjunto de elementos que se combinaram para configurar um determinado discurso. Assim, o pesquisador deve tomar cuidado para não se perder numa busca infinda pela origem dos eventos, ou por aqueles ditos fundadores que teriam o poder de determinar os rumos da história. Também deve ter em mente que as classificações e recortes são arbitrários e que aquilo que se torna visível num determinado momento é fruto de um jogo de forças que faz emergir determinadas formações enquanto deixa outras submersas. Como ressalta Al-Amoudi (2007), o trabalho de Foucault se voltava para o passado para (re) construir a história do presente. No mesmo sentido, Candiotto (2010) aponta que o passado que se faz presente é aquele que ressoa e faz sentido atualmente. Para o autor, um dos aspectos centrais do pensamento foucaultiano é a distinção entre saber e ciências, que é realizada a partir do método genealógico, que tenta mostrar momentos de ruptura em formas de saber que já foram bem estabelecidas.

De acordo com Candiotto (20I0), Michel Foucault estabeleceu suas discussões ao concentrar-se nos efeitos que as formações discursivas tinham sobre as práticas, apontando que as condições de emergência das verdades científicas são estabelecidas historicamente. Assim, determinadas formas de conhecer se estabelecem como legítimas, a depender das regras que regem as formações discursivas de seu tempo. Junto às regras está o poder, que se efetiva na medida em que as práticas obedecem ao bom uso das limitações que lhes são colocadas. Porém, o poder também permite a quem os tem ser mais incisivo no tocante à manutenção ou mudança dessas mesmas regras, o que poderia ser os pontos de inflexões ao longo da história (mas sem rupturas). Não que o poder seja precedente à capacidade de agir dentro das regras e sobre elas, existe uma relação dialógica entre ambos. Assim, "as ciências só encontram seu lugar e têm sua 
existência na prática discursiva, a qual, por sua vez, não depende daquelas para ser válida" (CANDIOTTO, 20IO, p. 48). Assim, é possível afirmar que os saberes reconhecidos como verdadeiros são sempre efeitos do poder.

Noutras palavras, o discurso qualificado como verdadeiro é aquele que se impôs sobre outros discursos relegando-os ao terreno do falso e do ilusório, instalando assim uma ordem. A ordem do discurso é o critério normativo para impor significações, identificar, dizer o que é verdadeiro e o que é falso, o que está certo e o que é errado [...] nada mais que um modo de operar separações (CANDIOTTO, 20I0, p. 50, grifo do autor).

Como aponta Foucault (2008), é ingrata a tarefa de tentar reconstituir o momento exato em que um dado discurso é apropriado por um grupo ou indivíduo estabelecendo uma ruptura definitiva em um domínio específico do saber. Assim, não se pretende neste trabalho estabelecer o momento exato da transição do saber prático e estranho aos critérios de cientificidade - apesar de ser um saber "empírico" -, mesmo porque é provável que esse momento seja insondável. Como apontam Barley e Kunda (I992) e Shenhav (I995), estudos que remetem ao que se chama hoje de Administração existem pelo menos desde as últimas décadas do século XIX, antes de as ideias tayloristas ganharem força.

Ao mesmo tempo, a formação do campo do saber administrativo não pode ser descolada das transformações nas fábricas desde a Revolução Industrial até o início do século XX - quando Taylor (I9I3) lança suas primeiras obras sobre a administração das oficinas. Contudo, ressalta-se que moralistas e economistas políticos ingleses já, em alguma medida, se preocupavam com a organização dos (e nos) locais onde era feita a produção de bens, como mostra, por exemplo, Foucault (I987), e como pode ser visto no clássico estudo de Smith (I983) sobre a riqueza das nações, particularmente a divisão do trabalho na fabricação de alfinetes. Entretanto, acredita-se que, ao longo do tempo e como forte impulso iniciado nos últimos anos do século XIX, a Administração passa a ser elaborada como uma disciplina à parte, que tinha suas conexões, mas também suas diferenças em relação a outras áreas do saber.

Ou seja: fatores diversos, relacionados ao desenvolvimento da sociedade, mas também às disputas pelo poder de falar "a verdade" sobre um objeto, levaram a Administração a se tornar, paulatinamente, um campo de saber complexo dotado de especificidades que permitissem que houvesse certo descolamento em relação a outros domínios da ciência. Nesse sentido, a Administração passa a ser um campo dotado de regras e especificidades que o diferenciam de outros, ao mesmo tempo que passa a obedecer às regras de produção de verdades científicas. 
Deve-se, contudo, considerar o alerta de Foucault (2008) de que, mesmo que os discursos tratem de objetos similares, não são necessariamente os mesmos objetos que são falados por cada discurso. Ou seja, as oficinas e fábricas dos séculos XVIII e XIX não são, necessariamente, representadas na época como o é uma indústria do século XXI. Para Foucault (2008, p. 55) importa "não mais tratar os discursos como conjuntos de signos (elementos significantes que remetem a conteúdos ou a representações), mas como práticas que formam sistematicamente os objetos de que falam". O próprio estabelecimento de um discurso em torno da gestão vivifica o que hoje é chamado por gestão. Ao mesmo tempo, pode-se pensar que por permanecerem tácitos, sem elaborações explícitas que deles se ocupassem, os saberes práticos não formam uma disciplina, não conseguem estabelecer firmemente o seu campo de poder.

Nesse sentido, Foucault (2009, p. 33) aponta que

[...] para pertencer a uma disciplina uma proposição deve poder inscrever-se em certo horizonte teórico [...]. No interior de seus limites, cada disciplina reconhece proposições verdadeiras e falsas; mas ela repele, para fora de suas margens, toda uma teratologia do saber.

Assim, uma vez que existem mecanismos para a validação da verdade, é evidente, também, que apenas algumas pessoas que ocupem determinadas posições estão autorizadas a proferir um discurso considerado verdadeiro (FOUCAULT, 2009).

Pode-se dizer que os lugares institucionais dos quais se profere o discurso que legitima o bacharel em Administração, seus saberes e suas práticas são a universidade, a fábrica (lato sensu) e os trabalhos que comparam, mensuram, elaboram e atestam quem pratica e quem não pratica a Administração, quem deve permanecer e quem deve ser transformado. Isso tudo se dá por meio de diversos mecanismos, e boa parte deles se liga ao aparelho escola. Foucault (2009, p. 45) questiona:

O que é afinal um sistema de ensino senão uma ritualização da palavra; senão uma qualificação e uma fixação dos papéis para os sujeitos que falam; senão a constituição de um grupo doutrinário ao menos difuso; senão uma distribuição e apropriação do discurso com seus poderes e saberes?

Além disso, aquilo que Foucault (2008) afirma sobre o médico exemplifica uma ideia que pode ser utilizada, por analogia, na compreensão de outras profissões. Segundo o autor, 
[...] [o] status do médico compreende critérios de competência e de saber; instituições, sistemas, normas pedagógicas; condições legais que dão direito - não sem antes lhe fixar limites - à prática e à experimentação do saber. Compreende, também, um sistema de diferenciação e de relações (divisão das atribuições, subordinação hierárquica, complementaridade funcional, demanda, transmissão e troca de informações) com outros indivíduos ou outros grupos que têm eles próprios seu status (com o poder político e seus representantes, com o Poder Judiciário, com diferentes corpos profissionais, com os grupos religiosos e, se for o caso, com os sacerdotes) (FOUCAULT, 2008, p. 56-57).

Assim, Foucault (I979, p. I22) atesta que o médico é “aquele que pode dizer a verdade da doença pelo saber que dela tem, e aquele que pode produzir a doença em sua verdade e submetê-la, na realidade, pelo poder que sua verdade exerce sobre o próprio doente". Do mesmo modo, entende-se que os bacharéis em Administração, e mesmo outros detentores de diplomas de graduação, passaram, em certa medida, a ter o direito de dizer a verdade sobre as práticas e estratégias de gestão.

Nesse sentido, é possível asseverar que, no espaço da academia no qual eram formados os bacharelandos, não havia mais lugar para aqueles cujo saber foi tachado de arcaico e inútil. "Aquilo que entre as ciências do homem é convencionado como verdadeiro, para Michel Foucault configura a justificação racional de sistemas excludentes de poder que atuam nas práticas institucionais e científicas" (CANDIOTTO, 20IO, p. 50). Devem-se aprender práticas condizentes com a evolução das técnicas, tecnologias e que, mais importante, fossem adequadas ao regime de verdade existente, para que pudesse tornar os futuros administradores homens do seu tempo. Foucault (I999, p. 8) afirma que as práticas sociais

[...] podem chegar a engendrar domínios de saber que não somente fazem aparecer novos objetos, novos conceitos, novas técnicas, mas também fazem nascer formas totalmente novas de sujeitos e de sujeitos de conhecimento. O próprio sujeito de conhecimento tem uma história, a relação do sujeito com o objeto, ou, mais claramente, a própria verdade tem uma história.

Note-se que a relação pedagógica é também uma relação de poder, na qual o professor busca estabelecer uma determinada maneira de o aluno ver o mundo e com ele se relacionar. Incorporando essa perspectiva, o aluno tende a reproduzila, passando a julgar o saber prático pelo mesmo viés que o faz a academia. Oakes, Townley e Cooper (I998, p. 272, grifo nosso, tradução nossa) apontam que o "poder da pedagogia reside na sua habilidade de nomear coisas de uma 
maneira que diminui a possibilidade de resistência porque o processo aparenta ser neutro e normal - técnico". Foucault (I999, p. 5I) explicita, a partir de um posicionamento nietzschiano, que "por trás de todo o saber, de todo o conhecimento, o que está em jogo é uma luta de poder. O poder político não está ausente do saber, ele é tramado com o saber". Assim,

[...] deixa de ser central a busca neutral da verdade ou ainda o combate pela verdade, em favor da verdade; importam os embates em torno da verdade, ou seja, o papel econômico e político que ela desempenha, A verdade neutra e essencial liberta do poder, não existe (CANDIOTTO, 20Io, p. 66, grifo do autor).

Há, posteriormente, uma disseminação por todo o tecido social dessa maneira de encarar o saber prático como pouco afeito às exigências da contemporaneidade e inexistente no interior das grandes empresas. Ora, tanto o saber prático existe no interior das organizações empresarias quanto não é possível que seja completamente abarcado nas formulações da academia, como mostram, por exemplo, as discussões em torno da estratégia percebida como prática social levadas a cabo por Jarzabkowski (2004) e Wilson e Jarzabkowski (2004). Entretanto, essas formulações, na medida em que visam estruturar os saberes práticos para torná-los mercadoria5, acabam por explicitar e aprofundar o modo como, muitas vezes, se dá a ligação da academia com os saberes práticos. Há uma apropriação desses saberes retirando o que neles há de específico para que seja possível reinseri-los no mercado (do ensino ou da consultoria, por exemplo) com elevado valor financeiro, ignorando que sua produção é atributo dos sujeitos e de suas interações sociais. Como salienta Candiotto (20I0, p. 76), "a verdade de um objeto só pode ser delimitada ao perguntar como ele foi construído, qual é sua história e não como é desvelado na origem essencial e preexistente".

\section{A FORMAÇÃO DO CAMPO DOS ESTUDOS EM ADMINISTRAÇÃO}

Como indicam Frenkel e Shenhav $(2003,2006)$, a teoria gerencial não é construída exclusivamente a partir de reflexões teóricas, pois busca também refletir algumas das práticas estabelecidas, de modo a legitimar umas enquanto marginaliza outras. Assim, ainda que se apresente na roupagem de ciência ou de técnica, a teoria administrativa se erige sobre práticas, por vezes controversas.

No site do grupo Strategy as Practice (s. d.), é possível ver a seguinte afirmação: “we share with traditional strategy research a concern for firm performance". 
Os autores salientam que toda teoria, para ser efetiva, deve ser apropriada e fazer sentido para as pessoas de um determinado lugar, do que decorre que ela é sempre uma adaptação a uma realidade contingente.

Para Motta (I986), a objetividade de qualquer teoria é sempre um aspecto questionável, já que todo conhecimento é socialmente construído, refletindo uma multiplicidade de práticas sociais. Mais especificamente, Astley (1985) afirma que o conjunto de conhecimentos que constituem a Administração é um produto socialmente construído. O autor atesta também que o progresso científico na área de Administração acontece a partir de processos subjetivos, nos quais os autores da área buscam, acima de tudo, a predominância de suas perspectivas em relação a outras.

Motta (I986) ressalta que as teorias administrativas refletem um conhecimento construído em torno de centros de consenso e com multiplicidades simuladas, já que tem que se submeter à hierarquia posta pelos critérios burocráticos que chancelam a cientificidade dos saberes ou os critérios paradigmáticos na visão de Astley (I985). Motta (I986, p. 58) afirma:

Altamente sistematizada, a teoria organizacional estabelece uma divisão de trabalho que distingue o "saber comum" do "saber científico", os leigos dos profissionais. Estabelece, da mesma forma, uma estratificação meritocrática que dá aos ocupantes dos níveis mais altos o direito de se referirem à área organizacional de forma autoritária e rígida.

É interessante observar que Piron e Couillard (1996) defendem que os pesquisadores se apropriam de conceitos que as pessoas utilizam para descrever seus afazeres e os traduzem em uma metalinguagem que permite avançar as generalizações analíticas, fazendo que os postulados se tornem mais gerais e, ao mesmo tempo, mais desligados das práticas. Os símbolos, os códigos, as ancoragens e as analogias utilizados trazem outros sentidos dos mais variados que não só desligam o indivíduo da prática, mas também que o distanciam dela ou não permitem que o próprio praticamente reconheça sua ação no postulado descrito. Nesse sentido, Astley (1985) aponta que as teorias administrativas se valem da ambiguidade e da abertura linguísticas para ampliar seu potencial de aceitação e disseminação.

Para Audet e Déry (I996), a busca pela legitimação científica dos saberes administrativos se deu principalmente a partir de 1950 , com o apoio das fundações Ford e Carnegie. Naquele momento, o saber contextualizado, normativo e concreto que dominava o campo, tendo como expoentes Frederick Taylor e Henry Fayol, por exemplo, passou a ser suplantado por elaborações descontextualizadas, analíticas e abstratas (AUDET; DÉRY, I996), mas que estavam calcadas em sua cientificidade, chancelada pela aproximação entre as escolas de 
Administração e a academia que aconteceu na mesma época, como apontam também Augier, March e Sullivan (2005).

Audet e Déry (1996) salientam que, no princípio, os autores da área de Administração se apropriaram do discurso científico para legitimar suas práticas e conseguir sujeitar a administração às "leis empíricas". A racionalização e a administração científica estabelecem as bases de uma praxeologia da ação administrativa, estabelecendo também certa engenharia do social (AUDET; DÉRY, I996; NOËL, 2007a). Assim, Shenhav e Weitz (2000) apontam que a Administração era entendida como instrumento para a efetivação da paz social e silenciamento dos conflitos. Tal entendimento era reforçado pelo verniz de ciência que as primeiras teorias administrativas sustentavam (BARLEY; KUNDA, I992).

Como aponta Ibarra-Colado (2006), contudo, os saberes produzidos na área não devem ser considerados meros resultados de práticas e procedimentos que revelariam a verdade dos objetos sobre o qual se debruçam. São, na verdade, saberes que refletem a hegemonia de certa forma de produzir conhecimentos, localizada geograficamente nos países centrais (especialmente nos Estados Unidos) e fruto de embates que decidem as visões corretas. Nesse sentido, Shenhav (I995) aponta que poucos pesquisadores se dedicaram a estudar o contexto no qual os saberes administrativos se desenvolvem e alcançam o status de consenso. É elucidativo o trabalho de Frenkel e Shenhav (2006) sobre o desenvolvimento desses saberes no Estado israelense após sua independência, que mostra como os significados de cada palavra são objeto de disputa.

Assim, considera-se que as teorias gerenciais são construídas como discursos que intentam estabelecer consensos na área a fim de, entre outras coisas, ampliar o espaço de poder de seus defensores, como aponta Astley (1985), e afastar posicionamentos dissonantes que possam ameaçar certo status quo. Ao mesmo tempo, ela não determina unilateralmente os objetos que cria (BARLEY; KUNDA, I992; AUDET; DÉRY, I996; PIRON; COUILLARD, I996). É um discurso que tem efeitos de verdade, que, ao dizer da realidade, contribui para conformá-la, conforme apontam Barley e Kunda (I992). Dessa maneira, não importa se debruçar sobre a veracidade dos saberes construídos sob a égide das ciências administrativas e sobre aquela dos praticantes, mas entender quais os efeitos de verdade produzidos por cada uma delas.

As teorias que versam sobre a administração ou sobre as organizações são, em geral, reproduzidas de forma descontextualizada (IBARRA-COLADO, 2006), ainda que mantenham sua capacidade de produzir efeitos sobre as práticas. Somese que, como apontam Jacques (2006) e Frenkel e Shenhav $(2003,2006)$, as teorias administrativas escamoteiam as bases sobre as quais se estabelecem, embora permaneçam, ainda que implicitamente, reproduzindo seus pressupostos. Exemplo disso é a constatação de Frenkel e Shenhav (2003) de que o autor da Escola de 
Relações Humanas, Elthon Mayo, estabelece boa parte de seus argumentos com base em uma visão que pressupõe diferenças entre as "raças" humanas.

Salienta-se, ainda, que, no mesmo momento em que a área de Administração passou a buscar se legitimar no interior da academia, estudiosos das organizações buscaram estabelecer bases que fornecessem subsídios para considerar as organizações como estruturas genéricas, a partir da interpretação parsoniana da obra de Max Weber (SHENHAV, 2003). Scott (2004) aponta que gradualmente as organizações passaram a ser vistas como um tipo genérico de estrutura social, que deveria ser gerenciado a partir de um corpo de conhecimentos comum, a Administração de matiz estadunidense, ou seja: o management, que paulatinamente foi sendo elaborado de forma mais distante dos problemas imediatos dos praticantes (NOËL, 2007b).

É interessante notar que Audet e Déry (1996) argumentam que os saberes dos praticantes foram revalorizados a partir da década de I980, na medida em que o indivíduo, como categoria sociológica e política, ganhava espaço nas discussões, conjuntamente ao avanço do cognitivismo. Contudo, os autores não discutem os possíveis efeitos do neoliberalismo, por exemplo, nessa reinserção do saber dos praticantes, tampouco debatem se eles são reconhecidos como grupo capaz de se reproduzir ou se são apenas indivíduos isolados e, nesse sentido, se distanciam das discussões propostas no presente trabalho. Isso porque, quando há referência aos saberes dos praticantes, aponta-se para os sujeitos que atuaram, especialmente, em meados do século XX e que adquiriam seus saberes mais em razão da vivência cotidiana do que da transmissão de conhecimentos por meio de aparelhos escolares, embora não se ignore a existência de escolas comercias, como afirmado anteriormente.

\section{O SABER ADMINISTRATIVO LOCALMENTE}

Conhecimentos institucionalizados do saber administrativo acadêmico foram (e são) usados no Brasil no ensino em Administração sem menção à herança aos saberes práticos, ainda que, em parte, eles tenham sido incorporados à área. Isso parece ter acontecido, em grande medida, pela desvalorização dos saberes práticos de brasileiros que não compunham o cenário das grandes empresas e indústrias ou que não concentravam capital econômico. Tais saberes, segundo Curado (200I), são classificados como "práticos", por não se adequarem às normas de produção da ciência ou da técnica.

Deixando de lado a busca pela especificidade do caso singular e sem buscar efetuar generalizações amplas, pretende-se abordar a relação existente entre os praticantes da administração como agentes sociais e a formação do campo dos 
estudos administrativos no Brasil. O campo do saber administrativo já estava em formação há alguns anos em países de industrialização anterior à brasileira, como exemplificam, por exemplo, o estudo de Barley e Kunda (I992) ou de Shenhav (I995) e, sob outra roupagem, os escritos de Taylor (I913), Fayol (I989) e Barnard (I97I), todos eles partindo da perspectiva da prática e da técnica e não do registro da ciência, que só passa a ser importante no cenário da produção dos saberes administrativos no período que sucede a Segunda Guerra Mundial (MARCH, 2007; AUGIER; MARCH; SULLIVAN, 2005).

Spiandorelo (2008) afirma que as práticas defendidas por Frederick Taylor passaram a ganhar mais espaço no Brasil no final da década de ıوıo, quando as relações entre os capitalistas e os trabalhadores se tornaram um pouco mais tensas. Ao mesmo tempo, salienta-se que tanto as formulações de Taylor quanto as de Fayol passaram a ser vistas como um conjunto de medidas necessárias para o avanço do país (SILVA, I958; VIZEU, 20IO).

Como, entretanto, apontam Zanetti e Vargas (2007), a apropriação desses conhecimentos produzidos alhures se deu de acordo com as especificidades locais, embora os autores da escola clássica e científica sejam referenciados a todo momento, buscando legitimação dos discursos. Nesse sentido, com base em Pierre Bourdieu, Miceli (2007, p. I6) afirma que

[...] a organização do mundo e a fixação de um consenso a seu respeito constitui uma função lógica necessária que permite à cultura dominante numa dada formação social cumprir sua função político-ideológica de legitimar e sancionar um determinado regime de dominação.

Assim, há um movimento que visa estabelecer os saberes oriundos da academia como superiores aos saberes práticos. Além disso, especificamente dentro do meio acadêmico, observa-se a predileção por saberes produzidos em outros países em detrimento da produção acadêmica brasileira. Da mesma forma, este movimento demarca uma superioridade das formas de gerir grandes empresas em comparação às utilizadas na gestão de micro e pequenas empresas, bem como nas organizações familiares. Tais práticas garantem e legitimam determinados discursos em relação a outros, e engendram processos de dominação que imbricam tanto a materialidade quanto os saberes (FRENKEL; SHENHAV, 2003).

Ao mesmo tempo, há um movimento por parte dos atores da área de Administração na tentativa de legitimar sua produção e mesmo seu espaço. Tal aspecto pode ser verificado na década de I950, quando se observa que várias escolas superiores de Administração começam a ser implantadas no país (SPIANDORELO, 2008; BERTERO, 2009), visando atender à demanda de, por um lado, profissionais qualificados e, por outro, sujeitos que tivessem seus conhecimentos legitimados.

Buscando reconstituir a história dos saberes gerenciais em São Paulo a partir de sua efetivação no campo da prática, Curado (200I) estabelece particulari- 
dades no desenvolvimento desses saberes. A autora afirma que diversas teorias e práticas assimiladas e reproduzidas no país não eram adequadas ao contexto social brasileiro, como já havia apontado Motta (1986), que atesta que o formato americanizado dos primeiros cursos superiores não se adequava às necessidades do Estado ou das empresas brasileiras então existentes.

Para Curado (200I, p. 3), a consolidação do saber administrativo brasileiro passa por três momentos distintos: o período do saber prático, até I955, "relacionado a uma não sistematização do saber administrativo no qual as ações dos gestores são baseadas na experiência"; o do saber tecnológico, a partir da década de I950 até a de I990, que "se caracteriza pela sistematização do saber administrativo, por intermédio da adoção e disseminação de sucessivos modelos de gestão"; e o saber plural, a partir da década de I990 quando "a univocidade do saber administrativo começa a ser questionada e substituída pela busca de um conjunto de saberes que melhor se adaptem à realidade de cada empresa".

Assim, com mudanças observadas nos cenários social e econômico, o saber prático perde sua legitimidade em relação a outras formas de saber, especialmente aqueles construídos sob a égide de padrões rigorosos de cientificidade, que só podem ser legitimados segundo um cânone específico. Dessa forma, em conformidade com a periodização de Curado (200I), que aponta que o saber prático decai a partir de I955, pode-se observar que, a essa época, já haviam sido implantados os primeiros cursos superiores em Administração no país (BERTERO, 2009; NICOLINI, 2003).

É importante evidenciar que o desenvolvimento das forças de produção e a consecutiva ampliação da complexidade relativa dos processos de gestão passaram a exigir saberes mais específicos de gestores e trabalhadores. Esse desenvolvimento se deu pelo aumento no número de funcionários dentro de um mesmo espaço físico, implementação de multinacionais e consequente intensificação da competição e desenvolvimento tecnológicos que abriram espaço para as escolas de negócio. Nelas, inicialmente, praticantes formados em outras áreas transmitiam seus saberes, legitimando-os. Dessa maneira, formaram-se gerações de bacharéis e professores no campo da Administração. Esses novos profissionais formados e a academia passam a atuar no sentido de legitimar tais saberes e práticas.

"Dar certo" não era mais suficiente. Passou a se fazer necessário que desse certo a partir de uma determinada perspectiva. É importante salientar que o movimento social que se procedeu parece ter "naturalmente" contribuído para a "elitização" do saber prático da seguinte maneira: um determinado praticante traz consigo, obviamente, os saberes que haviam sido construídos na prática cotidiana. Por vezes, para repassar esse saber, ele era estruturado e formalizado, passando a ser "propriedade" do empregador de maneira mais direta, como abordado por Bravermann (I98I).

Sabendo da importância das atividades comerciais na economia pouco industrializada, é interessante observar, conforme Dantas (2005), a forma pejorativa 
como é tratado o comerciante: como um profissional que aprendeu muita coisa "de ouvido", aprendeu aritmética pelo cálculo mental e estudou história pela via oral. Entendidas como ruins, essas características contribuem ainda mais para a deslegitimação do saber prático. Dantas (2005) salienta que comerciantes que prosperaram (ficaram ricos) se sentiam pouco à vontade com a imagem de ignorantes e analfabetos e tentaram evitar essa imagem.

Como apontam Truzzi (I992) e Cabreira (200I), é possível afirmar que os próprios praticantes tendem a, com o tempo, se esforçar para que seus filhos consigam adquirir saberes que são valorizados socialmente. Isso se dava, especialmente, pela educação formal proporcionada aos filhos, em especial por meio da obtenção de títulos das profissões mais valorizadas socialmente, como medicina ou direito. Os filhos, de posse do título de "doutor", seguem, em geral, atividades profissionais diferentes das do pai ou da mãe que trabalhavam no comércio. Truzzi (I992) e Cabreira (200I) indicam que mascates e representantes comerciais que atuavam em meados do século XX se preocupavam não apenas em acumular capitais financeiros, mas também em adquirir prestígio social por meio da educação dos filhos.

Nessa perspectiva, o fato de os praticantes do comércio "formarem os filhos" e vê-los virarem "doutores" mantém o status da família desfrutado, também, pelo patriarca. A partir do trabalho de Pierre Bourdieu, Dubar (2005, p. 83) afirma que o pequeno burguês

[...] concentra-se na família nuclear [...], investe muito na escola e impele sua progenitura ao maior êxito possível [...]. Desse modo, tudo o opõe ao (verdadeiro) burguês, que pode dar mostras de largueza (de despesas) e de largura (de idéias) porque tem ao mesmo tempo os meios (econômicos) e os códigos (culturais) para isso.

Ou seja: uma vez que as pessoas que ascendem economicamente pela via do trabalho muitas vezes não dispõem dos códigos culturais das elites, a educação de seus filhos assume um papel importante que não se restringe à obtenção de um diploma ou à aquisição de conhecimentos científicos. Pelo estudo dos filhos, a família consegue se aproximar e se apropriar de códigos culturais das elites. Torna-se possível aos pais manter uma visão positiva de si e das atividades que exerceram, já que foi por meio de seu trabalho que conseguiram amealhar riqueza e elevar seu status, ao mesmo tempo que garantiram a manutenção de sua condição social por meio da educação formal de seus filhos.

Dubar (2005) aponta que a transmissão de disposições paternas para os filhos que adquiriam capital cultural pela via do estudo pode não acontecer, o que amplia a possibilidade de sucesso da referida estratégia. Isso porque

[...] [um] filho de operário, por sua vez filho de camponês e totalmente propenso à ascensão social e a sair da condição operária, não será educado da mesma maneira 
que um filho de operário, também filho de operário e persuadido de que não pode sair da condição operária. Enquanto o primeiro poderá ter um "habitus pequeno burguês” mesmo sendo de origem operária, mas com uma socialização antecipatória de pequeno burguês -, o segundo terá um habitus operário “tradicional”. [...] Nessa [...] interpretação, o habitus não é essencialmente a cultura do grupo social de origem, mas a orientação da descendência (DUBAR, 2005, p. 80).

Assim como delineado nas palavras de Dubar (2005), pode-se observar que os filhos de praticantes do comércio podem ser "socializados" em um meio que valoriza a educação formal como atributo importante, tanto ao sujeito específico quanto ao grupo familiar ao qual ele pertencia. Esse elemento coincide com os apontamentos de Misockzy (200I, p. 6), para quem “as estratégias também dependem do estado da problemática, isto é, do espaço de probabilidades herdado de lutas anteriores, que tende a definir o espaço de tomadas de posição possíveis e a orientar a busca de soluções”. Essas estratégias contribuem, assim, para legitimar o saber do bacharel em face daquele construído pelo praticante. Ao mesmo tempo - e, também, por consequência -, o ambiente de negócios tende a se tornar mais complexo, em parte por causa da ampliação da concorrência. Assim, os negócios passam a demandar mão de obra que se enquadre nos parâmetros relacionados ao que é ser um bom administrador e o que esse bom administrador deve saber, o que amplia a demanda e incentiva a abertura de cursos com vistas à formação de profissionais na área.

\section{CONSIDERAÇÕES FINAIS}

Este trabalho buscou refletir sobre a construção do conhecimento administrativo a partir dos saberes práticos. Intentou-se, também, trazer elementos que permitissem reflexões a respeito de como se formou o campo da Administração, especialmente no espaço acadêmico. Embora a análise conduzida seja lacunar, o cenário apresentado não é fruto exclusivo da especulação e busca lançar luzes sobre o papel que os praticantes e seus saberes tiveram e tem na construção da administração, buscando ainda expandir a noção de quem pode ser identificado enquanto "administrador" para além dos estereótipos arraigados.

Cabe destacar que não se intentou situar no mesmo plano as técnicas administrativas atualmente empenhadas por gestores profissionais ou bacharéis em Administração e as práticas de outrora. Trata-se de fenômenos sociais e culturais diferentes, que não podem ser considerados equivalentes sem um esforço de identificar diferenças e semelhanças. Mesmo as práticas comerciais do presente - que poderiam ser observadas in loco - não são as mesmas daquelas identificáveis no passado, ainda que próximo. 
É, contudo, significativo constatar certa continuidade no comportamento humano, nas práticas levadas a cabo pelos homens na sua cotidianidade, no nível de seus saberes práticos. Não há um momento claro de ruptura entre os saberes práticos, que outrora faziam parte do leque recursivo do qual dispunham os praticantes, e os saberes que foram sendo encampados como propriedade da academia, e que são efetivados como best practices na contemporaneidade.

A busca por uma gênese dos saberes administrativos será, como já afirmado, sempre infrutífera, uma vez que ela jamais poderia ser identificada com clareza. Entretanto, considera-se de extrema relevância buscar elementos do passado histórico para compreender os processos que se desenrolam no presente. O esquecimento e/ou a desconsideração dos sujeitos que atuavam no passado, e por consequência de seus saberes e práticas, representa uma lacuna basilar na compreensão do desenvolvimento da gestão no país. Além disso, exonera as práticas sociais cotidianas constituídas na pessoalidade, nos laços afetivos, nas reinvenções e na criatividade desses sujeitos, que certamente configuram parte do arsenal/repertório de técnicas da Administração no Brasil.

Entende-se que pesquisadores que se interessem pelo assunto podem trazer contribuições à discussão, seja criticando as suposições de formação do campo aqui defendidas, seja trazendo outros elementos para a análise desse mesmo campo. Pode-se, mesmo, vir a colocar em questão o que quer a academia quando faz um chamamento à prática e adota como paradigma um modelo específico de cientificidade (MATTOS, 20I0). Questões que não concernem imediatamente à presente discussão, mas que a ela são paralelas. De toda maneira, é importante afirmar que, como um ensaio teórico, este texto se pretende, especialmente, um substrato para discussões futuras. Assim, seriam especialmente interessantes trabalhos que se dedicassem a realizar genealogias à moda foucaultiana, de objetos que concernem atualmente ao saber administrativo.

\section{APPROPRIATION OF MANAGERIAL KNOWLEDGE: AN ALTERNATIVE VIEW ABOUT THE DEVELOPMENT OF THE FIELD}

\section{ABSTRACT}

This work aims to present an alternative view concerning to establishment of managerial knowledge. Moreover, this work aims to highlight the relevance of practitioners-managers to the coursing of managerial knowledge, and even its appearance, in a context where there was not management course. Thus, 
the knowledge transference and its legitimacy had not been integrated yet to the construction science rules, but it has been established in some sense besides those senses that are legitimized into an institutional perspective. Firstly, this paper considers the importance of studies that adopt an approach to the management into a historical view, in order to discuss deeply at contemporary time. This is a theoretical and epistemological approach that has become stronger mainly in others countries - and recently incorporated by Brazilians researchers (COSTA; BARROS; MARTINS, 20IO). Later, this work presents the foucaultian perspective that was used to support us in some reflections, principally the purposes about the constitution of discourses and the establishment of knowledge. We believe that this reflection concern to establishment of a truth production regime, similar at a science production regime, is crucial to comprehend the omission of practitioners' knowledge in studies about managerial knowledge development. In this paper we used some elements to discuss about the constitution of knowledge managerial field, mainly its development in Brazil. We conclude that practical knowledge, even marginalized, has been important to the formation of managerial knowledge field, principally in the period before the establishment of this knowledge into scientifics truths production regime.

\section{KEYWORDS}

Management; Teaching; Knowledge; Foucault; History.

\section{APROPRIACIÓN DE LOS CONOCIMIENTOS DE GESTIÓN: UNA VISIÓN ALTERNATIVA SOBRE EL DESARROLLO DEL CAMPO}

\section{RESUMEN}

Este trabajo presenta una visión alternativa del establecimiento del conocimiento gerencial. Destacamos la importancia de los comerciantes para que la circulación del conocimiento administrativo, e incluso su constitución, en un contexto donde no había cursos de gerencia. En efecto, la transferencia del conocimiento y su legitimidad no habían sido integradas todavía a las reglas de la producción científica, sino que se ha establecido en un cierto sentido además de esos sentidos que se legitiman en una perspectiva institucional. En primer lugar, este trabajo considera la importancia de los estudios que adoptan las consideraciones para promover en estudio de la gerencia en una visión histórica, para discutir en una manera profunda en el tiempo contemporáneo sus cuestiones. Esta énfasis teórica y epistemo- 
lógica que ha llegado a ser más fuerte - principalmente en otros países - ha sido incorporado recientemente por los investigadores brasileños (COSTA; BARROS; MARTINS, 20Io). Segundo, este trabajo presenta la perspectiva foucaultiana que fue utilizada para apoyarnos en algunas reflexiones, principalmente los propósitos investigativos de la constitución de discursos y el establecimiento del conocimiento. Creemos que para la tarea de reflexión acerca del establecimiento de un régimen de la producción de la verdad, similar en un régimen de la producción de la ciencia, es crucial comprender la omisión del conocimiento de los comerciantes en estudios sobre el desarrollo del conocimiento gerencial. Con esto, señalamos algunos elementos para discutir la constitución del campo de conocimiento gerencial, principalmente su desarrollo en Brasil. Concluimos que ese conocimiento práctico, aún marginado, ha sido importante para la formación del campo de conocimiento gerencial, principalmente en el período ante el establecimiento de este conocimiento en régimen de la producción de las verdades científicas.

\section{PALABRAS CLAVE}

Gerencia; Enseñanza; Conocimiento; Foucault; Historia.

\section{REFERÊNCIAS}

AGUIAR, A. R. C. Saber camponês e mudança técnica: um estudo de caso junto a pequenos produtores do bairro de Cardoso, Poço Fundo, M. G. I992. Dissertação (Mestrado em Administração Rural)-Escola Superior de Agricultura de Lavras, Lavras, I992.

Al-AMOUDI, I. Redrawing Foucault's ontology. Organization, v. I4, n. 4, p. 543-563, Sept. 2007.

ASTLEY, W. G. Administrative science as socially constructed truth. Administrative Science Quarterly, v. 30, n. 4, p. 497-513, Dec. I985.

AUDET, M.; DÉRY, R. La science réfléchie. Quelques empreintes de l'epistemologie des sciences de l'administration. Antropologie et Sociétés, v. 20, n. I, p. I03-I23, jan./avr. I996.

AUGIER, M.; MARCH, J. G.; SULLIVAN, B. N. Notes on the evolution of a research community: organization studies in Anglophone North America, I945-2000. Organization Science, v. I6, n. I, p. 85 -95, Jan./Feb. 2005 .

BARLEY, S. R.; KUNDA, G. Design and devotion: surges of rational and normative ideologies of control in managerial discourse. Administrative Science Quarterly, v. 37, n. 3, p. 363-399, Sept. 1992. BARNARD, C. As funções do executivo. São Paulo: Atlas, I97I.

BERTERO, C. O. Pesquisa e ensino em administração. São Paulo: Eaesp/FGV, 2009. II5 p. Relatório de pesquisa.

BOOTH, C.; ROWLINSON, M. Management and organizational history: prospects. Management \& Organizational History, v. I, n. I, p. 5-30, Feb. 2006.

BRAVERMANN, H. Trabalho e capital monopolista: a degradação do trabalho no século XX. 3. ed. Rio de Janeiro: Jorge Zahar, I98I. 
BURKE, P. A escrita da História. São Paulo: Editora Unesp, I992.

CABREIRA, M. M. Cultura e identidade em São Paulo: a imigração síria e libanesa. EccoS Revista Científica, São Paulo, v. 3, n. I, p. 93-103, jan./jun. 200I.

CANDIOTTO, C. Foucault e a crítica da verdade. Belo Horizonte: Autêntica; Curitiba: Champagnat, $20 I 0$.

CARDOSO, C. F. S. Narrativa, sentido, história. Campinas: Papyrus, I997.

CARTER, C.; MCKINLAY, A.; ROWLISON, M. Introduction: Foucault, management and history. Organization, v. 9, n. 4, p. 515-526, Nov. 2002.

CERTEAU, M. A invenção do cotidiano: artes de fazer. Petrópolis: Vozes, 2008.

CHANDLER JR., A. Strategy and structure: chapter in the history of American industrial enterprise. Cambridge: MIT Press, I962.

CHANDLER JR., A.; TEDLOW, R. S. The coming of managerial capitalism: a casebook on the history of American economy institutions. Homewood: Irwin, I985.

COSTA, A. S. M. da; BARROS, D. F.; MARTINS, P. E. Perspectiva histórica em administração: novos objetos, novos problemas, novas abordagens. Revista de Administração de Empresas, v. 50, n. 3, p. 288-299, jul./set., 2010.

CURADO, I. B. O desenvolvimento dos saberes administrativos em São Paulo. 200I. Tese (Doutorado em Administração)-Fundação Getulio Vargas, São Paulo, 200I.

DANTAS, E. W. C. Apropriação do espaço público pelo comércio ambulante. Geo Crítica, Scripta Nova, Revista Electrónica de Geografia y Ciências Sociales, v. 9, n. 202, p. I-I6, dic. 2005. Disponível em: <http://www.ub.es/geocrit/sn/sn-202.htm>. Acesso em: Io abr. 20II.

DUBAR, C. A socialização: construção das identidades sociais e profissionais. São Paulo: Martins Fontes, 2005. $343 \mathrm{p}$.

FAYOL, J. H. Administração industrial e geral: previsão, organização, comando, coordenação, controle. São Paulo: Atlas, I989.

FOUCAULT, M. O nascimento da clínica. 2. ed. Rio de Janeiro: Forense Universitária, I979.

Vigiar e punir: nascimento da prisão. 5. ed. Petrópolis: Vozes, I987.

A verdade e as formas jurídicas. Rio de Janeiro: NAU Editora, I999.

A arqueologia do saber. 7. ed. Rio de Janeiro: Forense Universitária, 2008.

A ordem do discurso. I8. ed. São Paulo: Loyola, 2009.

FRENKEL, M.; SHENHAV, Y. From americanization to colonization: the diffusion of productivity models revisited. Organization Studies, v. 24, n. 9, p. I537-I56I, Nov. 2003.

From binarism back to hibridity: a postcolonial reading of management and organization studies. Organization Studies, London, v. 27, n. 6, p. 855-876, June 2006.

HONDA, L. Francisco Pinheiro: as atividades de um comerciante de grosso trato na América Portuguesa (I703 - I749). 2005. Dissertação (Mestrado em História Econômica)-Universidade Estadual de Campinas, Campinas, 2005 .

IBARRA-COLADO, E. Organization studies and epistemic coloniality in Latin America: thinking otherness from the margins. Organization, v. I3, n. 4, p. 463-488, July 2006.

JACQUES, R. S. History, historiography and organization studies: the challenge and the potential. Management and Organizational History, v. I, n. I, p. 3I-49, Feb. 2006.

JARZABKOWSKI, P. Strategy as practice: recursiveness, adaptation, and practices-in-use. Organization Studies, v. 25, n. 4, p. 529-560, May 2004. 
LAWRENCE, B. S. Historical perspective: using the past to study the present. Academy of Management Review, v. 9, n. 2, p. 307-312, I984.

LEBLEBICI, H.; SHAH, N. The birth, transformation and regeneration of business incubators as new organisational forms: understanding the interplay between organisational history and organisational theory. Business History, v. 46, n. 3, p. 353-380, July 2004.

MARCH, J. G. The study of organizations and organizing since I945. Organization Studies, v. 28, n. I, p. 9-I9, Jan. 2007.

MATTOS, P. L. C. L. Relações teoria-prática em Administração: o que desaparece nesse "Buraco Negro”. In: ENAPAD, 40., 20I0, Rio de Janeiro. Anais... Rio de Janeiro: Anpad, 20Io. p. I-I7.

MICELI, S. Introdução: a força do sentido. In: BOURDIEU, P. A economia das trocas simbólicas. São Paulo: Perspectiva, 2007. p. 7-6I.

MISOCKZY, M. C. A. Campo de poder e ação em Bourdieu: implicações de seu uso em estudos organizacionais. In: ENCONTRO NACIONAL DOS PROGRAMAS DE PÓS-GRADUAÇÃO EM ADMINISTRAÇÃO, 25., 200I, Campinas. Anais... Rio de Janeiro: Anpad, 200I. CD-ROM.

MOTTA, F. C. P. O autonomismo e a questão da organização. Revista de Administração de Empresas, Rio de Janeiro, v. 26, n. I, p. 57-66, Jan./Mar. I986.

NICOLINI, A. M. Qual será o futuro das fábricas de administradores? RAE - Revista de Administração de Empresas, São Paulo, v. 43, n. 2, p. 44-54, 2003.

NOËL, M. 80 ans de problématiques managériales: une exploration historico-scientométrique de la Harvard Business Review. In: CONFÉRENCE DE LA ASSOCIATION DES SCIENCES ADMINISTRATIVES DU CANADA, 50., 2007, Otawa. Otawa: Association des Sciences Administratives du Canada, 2007a.

Action et connaissance en management: une exploration épistémologique des roo bestsellers de la Harvard Business Review. In: CONFÉRENCE DE LA ASSOCIATION INTERNATIONALE DE MANAGEMENT STRATÉGIQUE, 6., 2007, Montreal. Montreal: Association Internacionale de Management Stratégique, 2007b.

OAKES, L. S.; TOWNLEY, B.; COOPER, D. J. Business planning as pedagogy: language and control in a changing institutional field. Administrative Science Quarterly, v. 43, n. 2, p. 257-292, June I998.

PAIVA, C. de A.; GODOY, M. M. Território de contrastes: economia e sociedade das Minas Gerais do século XIX. In: SEMINÁRIO SOBRE A ECONOMIA MINEIRA, IO., 2002, Diamantina. Anais... Belo Horizonte: Cedeplar/UFMG, 2002.

PELEIAS, I. R. et al. Evolução do ensino da contabilidade no Brasil: uma análise histórica. Revista Contabilidade \& Finanças, v. I8, p. I9-32, jun. 2007.

PIRON, F.; COUILLARD, M. A. Présentation. Les usages et les effets sociaux du savoir scientifique. Anthropologie et Sociétés, v. 20, n. I, p. 7-26, jan./avr. 1996.

RIBEIRO, M. M. L. Profissionalização e agropecuária: formas de apropriação de novas tecnologias. I995. Dissertação (Mestrado em Ciências Sociais)-Pontifícia Universidade Católica de São Paulo, São Paulo, I995.

Modo de produção e formação social: o caso do projeto "Volta ao Campo" em Pirassununga/ SP. 2003. Tese (Doutorado em Ciências Sociais)-Pontifícia Universidade Católica de São Paulo, São Paulo, 2003.

RIBEIRO, M. M. L. O.; CARRER, C. C.; NUNES, R. Contribuições para o enfrentamento das relações tecnicistas no gerenciamento de um programa de difusão de tecnologias para o pequeno 
agronegócio. In: CONGRESSO DA SOCIEDADE BRASILEIRA DE ECONOMIA E SOCIOLOGIA RURAL, 42., 2004, Cuiabá. Anais... Brasília: Saber, 2004. v. I, p. 533-533.

RODRIGUES, L.; GOMES, D.; CRAIG, R. Aula do comércio: primeiro estabelecimento de ensino técnico profissional oficialmente criado no mundo? In: ENCONTRO DA ASSOCIAÇÃO PORTUGUESA DE HISTÓRIA ECONÓMICA E SOCIAL (APHES), 22., 2002, Aveiro. Anais... Aveiro: Aphes, 2002. p. I5-I6. Disponível em: <http://www.egi.ua.pt/xxiiaphes/Artigos/a\%20Gomes\%20 \&20Lima.PDF>. Acesso em: I3 jan. 2010.

SAAS, S. A. Getting down to business: the development of the commercial curriculum at the wharton school in I910. Business and Economic History, v. I0, n. 2, p. 83-89, I981.

SANSON, J. R.; NICOLAU, J. A. Do ensino de técnicas comerciais ao ensino de economia em Santa Catarina. Análise, v. I7, n. 2, p. 297-312, jul./dez., 2006.

SCOTT, W. R. Reflections on a half-century of organizational sociology. Annual Review of Sociology, v. 30, n. I, p. I-2I, Aug. 2004.

SHENHAV, Y. From chaos to systems: the engineering foundations of organization theory, I8771932. Administrative Science Quarterly, v. 40, n. 4, p. 557-585, Dec. I995.

Fusing sociological theory with engineering discourse: the historical and epistemological foundations of organization theory. In: KNUDSEN, C.; TSOUKAS, H. (Ed.). The Oxford Handbook of organization theory: meta-theoretical 'perspectives. Oxford: Oxford University Press, 2003. p. I83-209. SHENHAV, Y.; WEITZ, E. The roots of uncertainty in organization theory: a historical constructivist analysis. Organization, v. 7, n. 3, p. 373-40I, Aug. 2000.

SILVA, B. Gênesis do ensino de administração pública no Brasil. Cadernos de Administração Pública, Rio de Janeiro, v. 49, p. 42, I958.

SMITH, A. A riqueza das nações: investigação sobre sua natureza e suas causas. São Paulo: Abril Cultural, I983.

SPIANDORELO, S. C. Fragmentos da constituição da profissão de administrador (1931-1966). 2008. Dissertação (Mestrado em Administração)-Universidade São Francisco, São Paulo, 2008.

TAYLOR, F. W. La direction de ateliers: etude suivie d'un mémoire sur l'emploi des courroies et d'une note sur l'utilisation des ingenieurs diplomes. Paris: H. Dunod, E. Pinat, I9I3.

TRUZZI, O. De mascates a doutores: sírios e libaneses em São Paulo. São Paulo: Sumaré, I992.

ÜSDIKEM, B.; KIESER, A. Introduction: history in organization studies. Business History, v. 46, n. 3, p. 32I-330, July 2004 .

VIZEU, F. Management no Brasil em perspectiva histórica: o projeto do IDORT nas décadas de I930 e I940. 2008. Tese (Doutorado em Administração)-Fundação Getulio Vargas, São Paulo, 2008.

Potencialidades da análise histórica nos Estudos Organizacionais Brasileiros. Revista de Administração de Empresas, v. 50, n. I, p. 37-47, jan./mar., 2010.

WILSON, D. C.; JARZABKOWSKI, P. Pensando e agindo estrategicamente: novos desafios para a análise estratégica. Revista de Administração de Empresas, São Paulo, v. 4, n. 4, p. 2I-3I, set. 2004. ZANETTI, A.; VARGAS, J. T. Taylorismo e Fordismo na indústria paulista: o empresariado e os projetos de organização racional do trabalho, I920-I940. São Paulo: Associação Editorial Humanista, 2007. 